\title{
Analytical Approach to the Selection of Performer of the Project: Classification of Problems and an Illustration of an Example
}

\author{
Zvonimir Božilović ${ }^{*}$, Nenad Nikolić ${ }^{2}$ \\ ${ }^{1}$ Graditelj-Inženjering d.o.o., Visoka 29, Beograd (Serbia) \\ ${ }^{2}$ Faculty of Organisational Sciences, Belgrade (Serbia)
}

This paper provides an improvement in previously exposed to the general classification problem of selection of performers on the project behind a set of potential performers who are qualified for the relevant works. Thereby, one performer is not selected for the project as a whole, but more performers. The basic requirement is that for any stage is selected only one performer. First, there are three groups of problems from the standpoint of time and costs, as well as the parameters of activities: 1) unique parameters, 2) unique variants of all parameters of all potential performers of the same activities, and 3) various variants of parameters at least for one performer in relation to the other (one or more) performers of the same stage. In the framework of each group of problems are considered two subgroups: a) each activity is pre-assigned by the performer, and b) at least to one activity is made selection among several potential performers: 1. All performers have sufficient capacities, and 2. Some performers (at least one or all) have limited capacities. The aforementioned cases are described by mixed-integer linear mathematical models with the corresponding binary variables, considering more criteria. Group (i) is consisted by the criteria for the duration of the project and project costs, as the criteria of higher level of significance. Group (ii) is the criteria of lower level of significance for the values of the works, respectively the costs of the performers, which is justified to introduce appropriate priorities. Here is performed the minimization of the project criteria (according to the method of PERT/COST) and conditional maximization of performers' costs that does not distort the realized values for the project criteria (method of $\varepsilon$-limitation). Here is being specified a set of all or only characteristical Pareto-optimal solutions among which is selected the most appropriate solution for application. The mathematical problems are defined for the last two problems and are proposed algorithms to solve them. When there is limited capacities of performes, it is indispensable first to solve the linear problem without such limitations, and then for each solution to use a standard softwear for Project Management (PM) and to harmonize the required and available capacities of performers. The selection of performers is illustrated by sufficient capacities on a hypothetical project.

Keywords: project, selection of several performers, classification of problems, multi-criteria optimization.

\section{INTRODUCTION}

Many foreign and domestic authors decompose the problem of project management. Well known is the extreme complexity of construction projects (see, for example, [1, 2]). It is present that, to a lesser extent are exposed the aspects of selection of the performers, especially if the same activity has more potential performers. Typically is pointed the three ways of contracting works in construction of buildings (public bidding, collection of bids and direct negotiations) and it points out that an investor independently decides which way to apply. For example, in [3] are presented analytical approaches to selection of one among more potential performers for the project as a whole, or for individual stages of the project. There has been applied the theory of multi-criteria optimization (see, eg. [4, 5]).

General classification problem of selection of performers on the project is exposed to [6, 9, 10-13], indicating the choice of one performer for the project as a whole (which cannot introduce their subperformer) and a selection of more performers by assigning appropriate project works. Some authors point out the other approach is more favorable which is explained in more details in continuation. Works
$[7,8]$ show the general mathematical models to the selected problems of performers' selection and their resolution on the hypothetical projects.

\section{CRITERIA PROBLEMS TO SELECTION OF MORE PROJECT PERFORMERS}

The problem of selection of the project performers can be considered in two sets of criteria groups. In doing so, it often favourites appropriate potential performers.

The criteria of the project are to minimize the duration of the project and minimize project costs. In essence, if you are familiar with the time and costs of activities, project costs are known and is determined a plan with the minimum duration of the project. If at least one activity has a variety of time with appropriate costs, there is the problem of simultaneous minimization of the duration of the project costs of the project.

The criteria of potential performers usually are maximizing the value of their works, respectively maximizing carried out cost activities. In practice may be present and other requirements of performers. Eg., a particular performer expresses the desired minimum or maximum period of participation in the project (possibly given period), the earliest start to participate 
in the project or given date, tha latest participation in the completion of the project or given dates, etc.

Paragraph 1. The criteria of the project have a greater degree of significance in relation to the criteria of potential performers. After examining the criteria of performers it is not allowed to deteriorate the criteria of the project.

Paragraph 2. Potential performers may be equal to each other or to be assigned by the appropriate priorities. In the second case, the particular group of performers can be assigned by identical priorities. Also, it is possible to define several groups of performers including the following characteristics: (a) the different priorities of the group, and (b) all equal performers in the framework of the observed groups.

Paragraph 3. The main characteristic of the selection of more performers on the project is that for any observed activity or type of work, must be choose only one performer. If there are more alternatives for the time and costs of the observed activity, must be selected only one alternative.

\section{ANALYTICAL APPROACH TO SELECTION OF MORE PERFORMERS OF THE PROJECT}

Let be considered a project with $m$ parts (phases) marked with $A_{i}, \quad i \in I=\{1, \ldots, m\}$. Let the potential performers on the project be marked with $B_{j}$ and their number amounts to $n, j \in J=\{1, \ldots, n\}$. The performers of the project can be equal to each other with determined priorities depending on the successful participation to other projects of the same owner or investor, as well as other criteria (technical-technological equipment, human resources, participation in other people's projects, etc.). Let them in general case have a strict lexicographic order according to ascending order of their indices $\left(B_{1}>B_{2}\right.$ $>>\ldots>>B_{n}$ ), when $B_{1}$ has the highest and $B_{n}$ the lowest priority. In practice, it is often assumed that more performers to be of the same priorities.

Furthermore, some phases of $A_{i}$ have $n_{i}$ potential performers $B_{j}$ qualified for relevant works, $1 \leq n_{i} \leq n$, $j \in J_{i} \subseteq J, \quad i \in I . \quad$ Subgroup $J_{i}$ contains indices of corresponding $B_{j}$. Therefore, each $B_{j}$ may be potential for $m_{j}$ phase $A_{i}, \quad 1 \leq m_{j} \leq m, i \in I_{j} \subseteq I, j \in J$. Subgroup $I_{j}$ contains indices of corresponding $A_{i}$. In limiting cases occur the following variants:

$n_{i}=1$, is known $B_{j}$ for observed $A_{i}$ and a subgroup $J_{i}$ has only one member, $j \in J_{i} \subset J, i \in I_{j}$,

$n_{i}=n$, svi $B_{j}$ are potentials for the given $A_{i}$, so it applies to $j \in J_{i}=J, i \in I_{j}$,

$m_{j}=1$, determined $B_{j}$ can carry out only one $A_{i}$ and a subgroup $I_{j}$ with one member, $i \in I_{j} \subset I, j \in J_{i}$,

$m_{j}=m$, some $B_{j}$ can carry out all $A_{i}$, that's why $i \in I_{j}=I, \quad j \in J_{i}$.

\subsection{Classification of selection problems of more} performers

The aforementioned problems of selection can be classified into three groups 1) to 3) from the viewpoint of characteristic parameters $t_{i}$ for duration and $c_{i}$ for the costs of stages $A_{i}, \quad i \in I, \quad j \in J_{i}$ (Table 1). Each group is composed of two types of problems, a) and b), depending on whether $A_{i}$ has one (known) or more potential performers of $B_{j}$. Every problem has two types, 1and 2, from the viewpoint of capacity limitation or other limitations for the potential performers of $B_{j}$ on the project (such as the terms of engagement, the overall value of the assigned works, etc.), $j \in J$.

Tabela 1. Opšta klasifikacija problema izbora izvođača projekta

\begin{tabular}{|c|c|c|c|}
\hline \multirow{2}{*}{$\begin{array}{l}\text { Parameters of stage } A_{i} \\
\text { (time and costs) }\end{array}$} & \multirow{2}{*}{$\begin{array}{l}\text { Potential features of } B_{j} \\
\text { to perform } A_{i}\end{array}$} & \multicolumn{2}{|c|}{ Capacities for $B_{j}$} \\
\hline & & Sufficient & Limited \\
\hline \multirow{2}{*}{ 1) Unique parameters } & a) every $A_{i}$ known $B_{j}$ & P.1.a.1 & P.1.a.2 \\
\hline & b) at least one $A_{i}$ with more $B_{j}$ & P.1.b.1 & P.1.b.2 \\
\hline \multirow{2}{*}{ 2) Unique variants $D_{i v}$ of all $B_{j}$ for the same $A_{i}$} & a) every $A_{i}$ known $B_{j}$ & P.2.a.1 & P.2.a.2 \\
\hline & b) at least one $A_{i}$ with more $B_{j}$ & P.2.b.1 & P.2.b.2 \\
\hline \multirow{2}{*}{$\begin{array}{l}\text { 3) Various variants } D_{i j v} \text { At least of one } B_{j} \text { for } \\
\text { the same } A_{i}\end{array}$} & a) every $A_{i}$ known $B_{j}$ & Р.3.а.1 & P.3.a.2 \\
\hline & b) at least one $A_{i}$ with more $B_{j}$ & P.3.b.1 & P.3.b. 2 \\
\hline \multicolumn{2}{|c|}{$\begin{array}{l}\text { Warning 1. Trivial cases are excluded: every } A_{i} \text { known performer } B_{j} \text { and known variant } D_{i v} \text { under } \\
\text { 2), respectively } B_{j} \text { and } D_{i j v} \text { under 3) }\end{array}$} & \multicolumn{2}{|c|}{$\begin{array}{l}\text { Numeration of } \\
\text { problems and } \\
\text { mathematical } \\
\text { models }\end{array}$} \\
\hline
\end{tabular}

Group of problems 1) has unique parameters $t_{i}$ and $c_{i}$ on the same stage $A_{i}, i \in I$. Clearly, for type a) does not raise a problem to selection of performer $B_{j}$, since they're assigned for each $A_{i}, \quad i \in I, \quad j \in J_{i}$. It is necessary to determine the minimum duration of the project $T_{p}^{\text {min }}$ based on dependency of stages and their activities, and then 
calculate the relevant total costs of the project $C_{p}\left(T_{p}^{\min }\right)$ and costs $C_{j}\left(T_{p}^{\min }\right)$ for performers $B_{j}, \quad j \in J$. The presence at least of one $A_{i}$ with more potential $B_{j}$ in problems of the type b) enables optimization of values of the works, respectively maximization of costs $C_{j}\left(T_{p}^{\min }, C_{p}\left(T_{p}^{\min }\right)\right)$ for preferred $B_{j}$ on the project in the framewoek of the known values $T_{p}^{\min }$ and $C_{p}\left(T_{p}^{\min }\right), j \in J$. Type 1 of the problem (P.1.a.1 and P1.b.1) does not consider limitation for performers. For type 2 (P.1.a.2 and P.1.b.2) introduce restriction for some or for all potential performers $B_{j}$ on the project, primarily, from the standpoint of their limited capacities, expressed in number of hours of engagement $w_{j 0}(t)$ or with the required number of resource units $u_{j 0}(t)$, in each unit of time of $t$ on the project $(t=1,2, \ldots)$ or on the part of the project, $j \in J$.

Warning 2. All problems of type 2 (with limitation for performers) are characterized by the possibility to occur $T^{*}>T_{p}^{\min }$, longer duration of project $T^{*}$ in relation to its minimum duration $T_{p}^{m i n}$ for a problem type 1 (no limitation for performers). Namely, type 1 expands to type 2 , so the solving is conducted sequentially: in the first stage is solved the problem of type 1 and in the second stage it is going on to solve the problem of the type 2 .

Warning 3. The presence of more variants for the stages (Figure 1.1 to 1.4) in groups of problems 2) and 3), in accordance with rules of the method PERT/COST (in literature of English language it often has the name 'Project Crashing Method' and 'Time-Cost Trade-Off Problem') enable to determine the final number of various values for duration and the costs of the project (Figure 1.5). In the framework of these values (higher level criteria) is performed cost optimization of the favoured performers (lower level criteria), based on the selection of performers and/or variant parameters.

When tere are variants for time and costs of activities, the following terms are used:

Normal or maximum duration of the $\left(t_{n}\right)_{i}$ activities of $A_{i}$ have normal or minimal costs $\left(c_{n}\right)_{i}$.

Forced (shortened) or a minimum duration of the $\left(t_{u}\right)_{i}$ activities have forced or maximum costs of $\left(c_{u}\right)_{i}$.

$$
\begin{gathered}
\Delta c_{i v}=c_{i v}-c_{i, v-1}, i \in I, v=1,2, \ldots \\
c_{i v}^{L}(t)=-a_{i v} t+b_{i v}, i \in I, v=1,2, \ldots \\
\Delta c_{i v}^{(k), L}=a_{i v}=\frac{c_{i v}^{(1)}-c_{i, v+1}^{(1)}}{t_{i, v+1}^{(1)}-t_{i v}^{(1)}}, i \in I, v \in 2,3, \ldots, k \in 2,3, \ldots \\
b_{i v}^{k}=\frac{c_{i v}^{(1)} t_{i, v+1}^{(1)}-c_{i, v+1}^{(1)} t_{i v}^{(1)}}{t_{i, v+1}^{(1)}-t_{i v}^{(1)}} \quad, v \in 2,3, \ldots, k \in 2,3, \ldots
\end{gathered}
$$


The method of PERT/COST enables to shorten only indispensable activities and determine optimal costs of the project for the appropriate times (Figure 1.5):

The minimum total project costs for each permissible duration of the project.

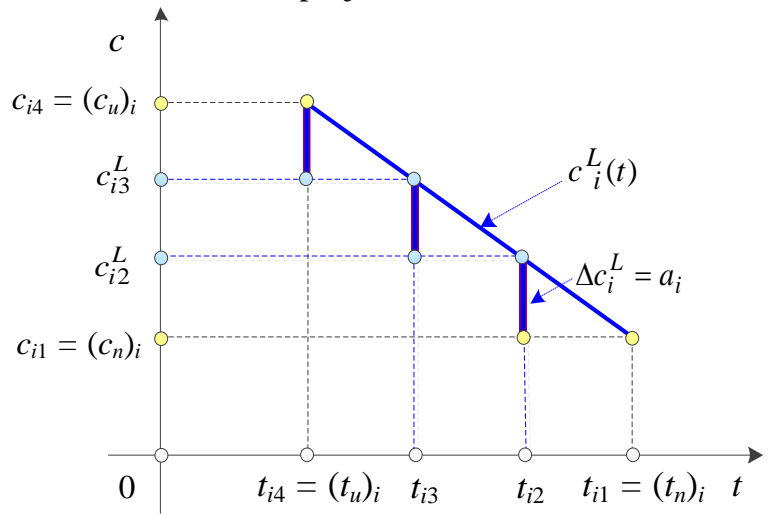

Slika 1.1

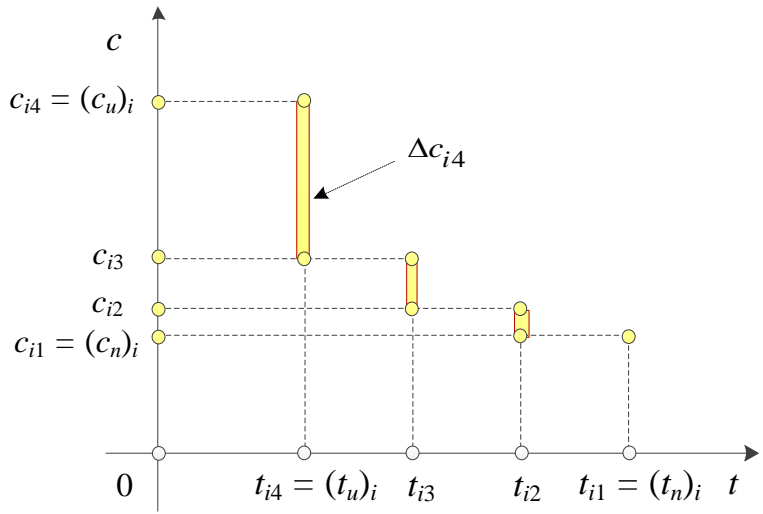

Figure 1.3

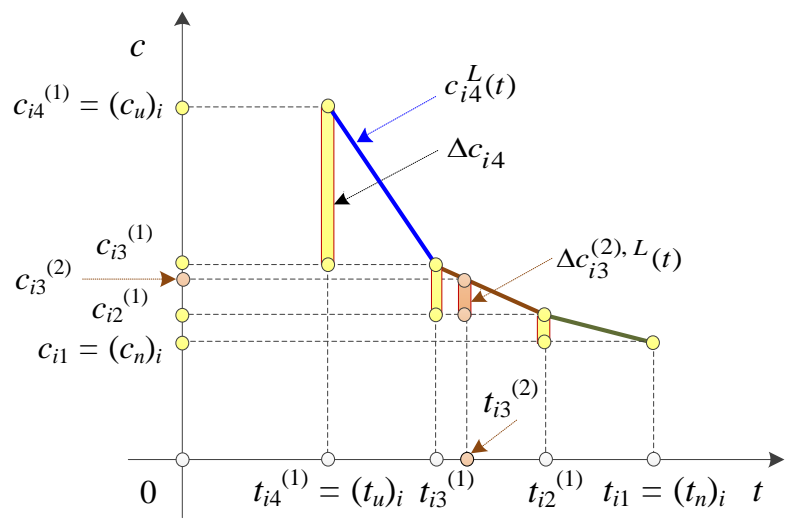

Figure 1.4

Group of problems 2) imply certain or all stages $A_{i}$ (or one at least $A_{i}$ ) with more variants $D_{i v}$ for times $t_{i v}$ and costs $c_{i v}, i \in I, v \in V_{i}=\left\{1, \ldots, d_{i}\right\}$. Here $d_{i}$ marks the number of variants $D_{i v}$ for the observed $A_{i}, \quad i \in I$. Parameters with $D_{i v}$ are identical for the all potential performrs of $B_{j}$ on the observed $A_{i}, i \in I, j \in J_{i}, \quad v \in V_{i}$. The problems of type a) with $n_{i}=1$ require selection of variants $D_{i v}$ for each $A_{i}$. The type b) of the problem
Lesser total project costs $C_{u}{ }^{*}=C_{p} *(m)$ for its forced duration, $C_{u}{ }^{*}<C_{u}$, if it is not necessary that all activities to be reduced to the forced times.

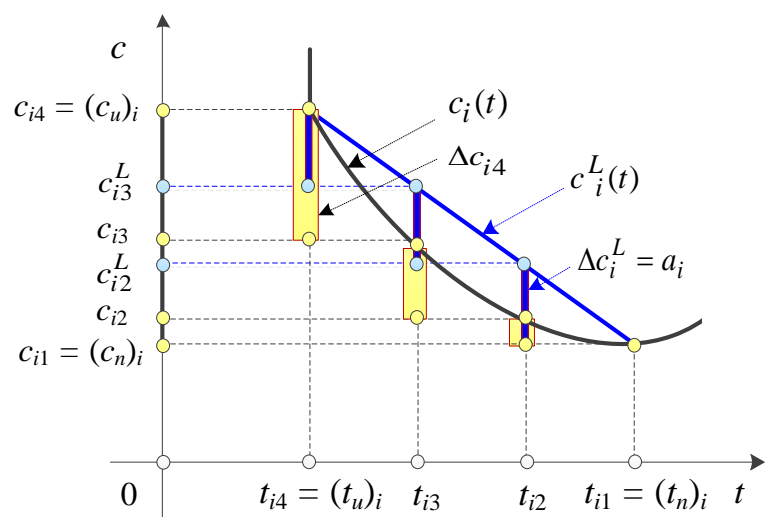

Figure 1.2

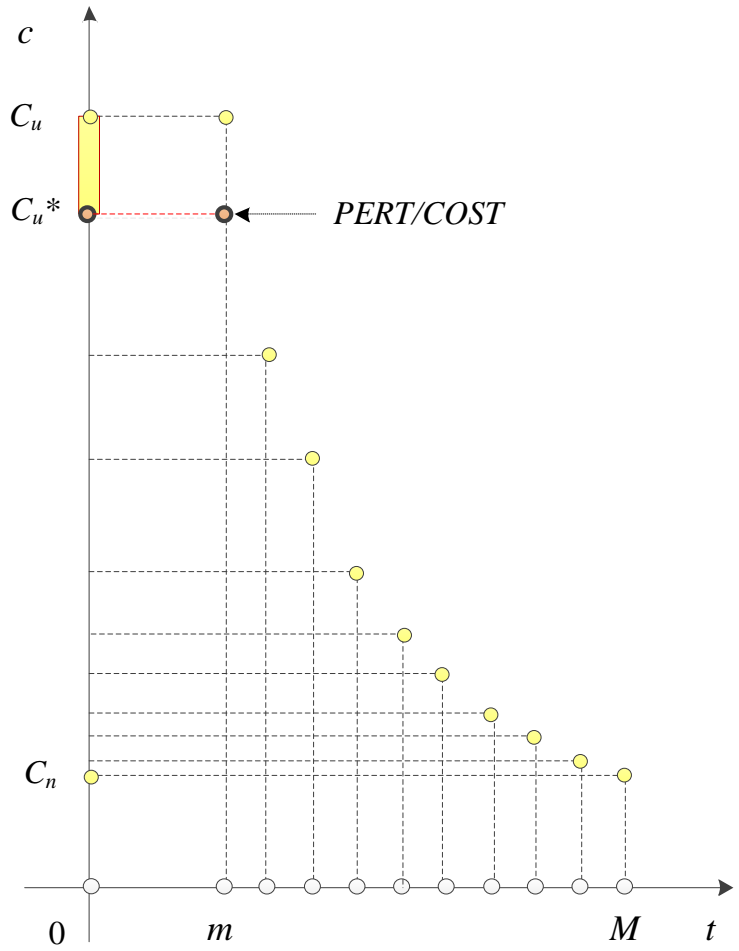

Figure 1.5

imposes selection of $D_{i v}$ andi $B_{j}$ for $A_{i}$ with $n_{i}>1$, as well as the selection only for $D_{i v}$ for the remaining $A_{i}$ with $n_{i}=1$ if such exist.

Group of problems 3) has at least one stage $A_{i}$ with more variants $D_{i j v}$ for the times $t_{i j v}$ and the costs $c_{i j v}, \quad i \in I, \quad v \in V_{i j}=\left\{1, \ldots, d_{i j}\right\}$. With $d_{i j}$ is marked the number $D_{i j v}$ of the potential performers of $B_{j}$ for the 
observed $A_{i}, \quad i \in I, \quad j \in J_{i}$. Now exists at least one $A_{i}$ of various parameters with $V_{i j}$ at least in a pair of potential $B_{j}, \quad i \in I, \quad j \in J_{i}$. Eg., $B_{j_{1}}$ and $B_{j_{2}}$ with $j_{1}, j_{2} \in J_{i}$ can perform $A_{i}$, and applies: (i) $t_{i j_{1} v} \neq t_{i j_{2} v}$ and $c_{i j_{1} v}=c_{i j_{2} v}$, or (ii) $t_{i j_{1} v}=t_{i j_{2} v}$ and $c_{i j_{1} v} \neq c_{i j_{2} v}$, or (iii) $t_{i j_{1} v} \neq t_{i j_{2} v}$ and $c_{i j_{1} v} \neq c_{i j_{2} v}$. If the problems of the type a) have $n_{i}=1$, is selected $D_{i j v}$ of each $A_{i}$. With the problems of the type b) with $n_{i}>1$, for appropriate $A_{i}$, is selected $D_{i j v}$ if $d_{i j}=1$, respectively $B_{j}$ and $D_{i j v}$ if $d_{i j}=1$. If there exist $A_{i}$ with $n_{i}=1$ and $d_{i j}=1$, selection is known with the given $B_{j}$ and its $D_{i j v}$ with one variant of parameter. The types of problems from the point of restriction of performers are valid by previously given interpretation.

3.2. Mathematical models and algorithms for solving of problems

With the all afore-mentioned problems we have defined the relevant general multi-criteria mathematical models of the type of mixed-integer linear programming (including specific binary variables) and set the algorithms of their solution. In continuation we consider the last two problems from the group 3 (3.b.1 and 3.b.2).

Paragraph 4. Modeling and solving of these problems are based on the use of of appropriate binary variables.

Binary variables of the first type $h_{i j v}$ in models

3.b.1 and 3.b.2 have an intention to identify which performer and which his variant of time and costs is selected for the observed activity. The values are $h_{i j v}=1$ (if for $A_{i}$ is selected $B_{j}$ with $D_{i j v}$ ), or $h_{i j v}=0$ (on the contrary), $i \in I, \quad j \in J_{i}, \quad v \in V_{i j}$. Namely, $h_{i j v}=0$ remains if for $A_{i}$ is not selected $B_{j}$ with $D_{i j v}$. There are two possibilities: (i) is selected $B_{j}$ with a certain variant of parameter which is various from $D_{i j v}$, or (ii) is selected any other performer, but not the observed $B_{j}$.

Binary variables of the second type $h_{i j v}(t)$ in a model of 3.b.2 distinguish the activities that are performed in teh observed unit of time $t$. They have values $h_{i j v}(t)=1$ (if is $h_{i j v}=1$ and $A_{i}$ is performed in the unit of time $t$ ), or $h_{i j v}(t)=0$ (on the contrary), $i \in I, j \in J$, $v \in V_{i j}, t \in T$. There occurs $h_{i j v}(t)=0$ in the following cases: (i) $h_{i j v}=1$, but $A_{i}$ is not performed in $t$, or (ii) $A_{i}$ is performed in $t$, but is $h_{i j v}=0$.

Paragraph 5. The essential characteristic of the problems, that for one $A_{i}$ must be choosen only one $B_{j}$ and that can be used only one $D_{i j v}$, expresses a condition of a form $\sum_{j \in J_{i}} \sum_{v \in V_{i j}} h_{i j v}=1, \quad i \in I \quad$ (the sum of all $h_{i j v}$ is 1). With this rule is performed three tules for calculation of the following values:

$$
\text { duration of activitiea } t_{i}=\sum_{j \in J_{i}} \sum_{v \in V_{i j}} t_{i j v} \cdot h_{i j v},
$$

$i \in I$,

costs of activities $c_{i}=\sum_{j \in J_{i}} \sum_{v \in V_{i j}} c_{i j v} \cdot h_{i j v}$, $i \in I$,

required operational capacities of performers in the unit of time of the project (expressed in number of units of capacity) $\sum_{i \in I} \sum_{v \in V_{i j}} u_{i j v}(t) \cdot h_{i j v}(t), j \in J, t \in T$.

Paragraph 6. Potential performers of $B_{j}$, who have $n$, are observed from the standpoint of their total costs $C_{j}, j \in J$. It must be kept in mind that performers are assigned appropriate priorities and is aptly to define their indices in accordance with the priorities, starting with favoured performers. Let be favoured performers with the indices in the group $\mathrm{J}^{+}$. To these performers are performed maximization of costs in the model of 3.b.1 and 3.b.2. There are two possibilities.

$n^{+}=n$, favouring all potential performers $B_{j}$, $j \in J^{+}=J$,

$n^{+}<n$, not favouring all potential performers $B_{j}$, so that for the favoured performers is valid $j \in J^{+}=\left\{1, \ldots, n^{+}\right\}$i $J^{+} \subset J=\left\{1, \ldots, n^{+}, \ldots, n\right\}$. It can be said that the non-favouring performers with the indices $j \in J \backslash J^{+}=\left\{n^{+}+1, \ldots, n\right\}$ have the lowest priority.

Paragraph 7. Potential performers can have limited operational capacities from the resource standpoint of the type of 'labor' or 'work' (man power and machinery), which considers the model 3.b.2. Let has $n^{-}$performers $B_{j}$ with the limited capacities and the indices of such performers make a group $J^{-}$. Applies $j \in J^{-}$with the characteristics from continuation.

Limited capacities may have all potential performers (occurs $n^{-}=n$ ), or just any potential performers (present is $n^{-}<n$ ),

Limited capacities may have favoured and nonfavoured performers,

Limited capacities must be considered indipendantly whether such feature have the favoured or the non-favoured performers.

\subsubsection{General mathematical model of problems 3.b.2}

Is performed an optimization of $2+n^{+}$criteria: project duration minimization (1), project costs duration (2), and costs maximization of favoured performers (3.j). 
Uknown or variables are: binary variables $h_{i j v} \mathrm{i}$ duration of project $T_{p}$ that simultaneously expresses $h_{i j v}(t)$, commencement and ending for $A_{i}\left(x_{i}, y_{i}\right)$, criterion (1). commencement and ending for $A_{\lambda}\left(x_{\lambda}, y_{i}\right)$, and

$$
\begin{gathered}
\min _{p}(h)=T_{p} \\
\min C_{p}(h)=\sum_{i \in I} \sum_{j \in J_{i}} \sum_{v \in V_{i j}} c_{i j v} \cdot h_{i j v} \\
\max C_{j}(h)=\sum_{i \in I} \sum_{v \in V_{i j}} c_{i j v} \cdot h_{i j v}, j \in J^{+}
\end{gathered}
$$

p.o.

$$
\begin{aligned}
& x_{i} \geq 0, i \in I \wedge R_{i}^{-}=\varnothing \\
& x_{i} \geq y_{\lambda}, i \in I \wedge R_{i}^{-} \neq \varnothing \\
& y_{\lambda}=x_{\lambda}+\sum_{j \in \Lambda_{j}} \sum_{v \in V_{\lambda j v}} t_{\lambda j v} h_{\lambda j v}, \lambda \in R_{i}^{-} \neq \varnothing, i \in I \\
& y_{i}=x_{i}+\sum_{j \in I} \sum_{v \in V_{i j}} t_{i j v} \cdot h_{i j v}, i \in I \\
& y_{i} \leq T_{p}, i \in I \wedge R_{i}^{+}=\varnothing \\
& \sum_{j \in J_{i}} \sum_{v \in V_{i j}} h_{i j v}=1, i \in I \\
& \sum_{i \in I} \sum_{v \in V_{i j}} u_{i j v}(t) \cdot h_{i j v}(t) \leq u_{j 0}(t), j \in J^{-}, t \in T \\
& h_{i j v}=\left\{\begin{array}{ll}
1, & A_{i} \rightarrow\left(B_{j} \rightarrow D_{i j v}\right) \\
0, & \text { otherwise }
\end{array} i \in I, \quad j \in J_{i}, \quad v \in V_{i j}\right. \\
& h_{i j v}(t)=\left\{\begin{array}{ll}
1, & h_{i j v}=1 \wedge A_{i} \text { at } t \\
0, & \text { otherwise }
\end{array} i \in I, \quad j \in J_{i}, \quad v \in V_{i j}, \quad t \in T\right. \\
& x_{i}, y_{i} \geq 0, i \in I \text {, } \\
& x_{\lambda}, y_{\lambda} \geq 0, \lambda \in R_{i}^{-} \neq \varnothing, i \in I \\
& T_{p} \geq 0
\end{aligned}
$$

where: $\left(t_{i j v}, c_{i j v}\right)$ duration and costs of activities of $A_{i}$ if is chosen the performer $B_{j}$ with the variant $D_{i j v}, \quad i \in I, \quad j \in J_{i}, \quad v \in V_{i j}, \quad x_{i}$ beginning $A_{i}, \quad i \in I, \quad y_{i}$ ending $A_{i}, \quad i \in I, R_{\dot{i}}^{-}$sum of indices $\lambda$ for activities of 'predecessors', ie. Activities of $A_{\lambda}$ from which depends $A_{i}, \quad \lambda \in R_{i}^{-} \neq \varnothing, \quad i \in I, \quad\left(x_{\lambda}, y_{\lambda}\right)$ beginning and ending of $A_{\lambda}, \lambda \in R_{i}^{-} \neq \varnothing, \quad i \in I, t_{\lambda j v}$ duration of $A_{\lambda}$ if is selected the performer $B_{j}$ including the variant $D_{\lambda j v}, \lambda \in R_{i}^{-} \neq \varnothing$, $i \in I, \quad j \in J_{\lambda}, \quad v \in V_{\lambda j}, \quad R_{i}^{+}$sum of activity index of 'sucessors' of the observed $A_{i}$, ie. Activities that depend from $A_{i}, i \in I, T_{p}$ duration of the project, $t$ unit of time on the project, $T$ sum of units in time, $t \in T=\left\{1, \ldots, T_{p}\right\}$, $u_{i j v}(t)$ engagement of operational capacities of the performers $B_{j}$ in the unit of time $t$ on $A_{i}$ with the variant $D_{i j v}$ for $t_{i j v}$ and $c_{i j v}, i \in I, \quad j \in\left\{J_{i} \cap J^{-}\right\}, v \in V_{i j}, \quad t \in T$, $u_{j 0}(t)$ available operational capacities of the performer $B_{j}$ in the unit of time $t, j \in J^{-}, t \in T$.

Restrictions have the following meanings: (4) determines the beginning of the starting activities of $A_{i}$ which does not depend on other activities $\left(A_{i}\right.$ has $R_{i}^{-}=\varnothing$ ), (5) defines that the beginning of $A_{i}$ with dependencies of (has $R_{i}^{-} \neq \varnothing$ ) cannot be earlier from the ending of its each predecessors $A_{\lambda}, \lambda \in R_{i}^{-}$, (6) calculates ending of each $A_{\lambda}$ (beginning plus duration) for application in (5), (7) forms ending of each $A_{i}$ (beginning plus duration), (8) conditions that the project duration of $T_{p}$, respectively the ending of the project cannot be earlier than the end of each completed $A_{i}$ without followers (without further activities, there is $R_{i}^{+}=\varnothing$ ), (9) provides that any of $A_{i}$ can perform only one $B_{j}$ using only one $D_{i j v},(10)$ conditions that utilization of capacities of each performers of $B_{j}$ in any unit of time does not exceed its available capacity, (11) defines binary 
variables of the first type, (12) defines binary variables of the second type, (13.1) and (13.2) are natural conditions on non-negativity of the real variables for initial activities of $A_{i}$ and $A_{\lambda}$, respectively, and (14) is a condition for the real variable that express duration of the project. The aforementioned variables receive integer values, when are integer numbers of variants $t_{i j v}$ during the activity times.

Paragraph 8.1. The model does not contain a definition of the latest completion of the project and nonlinear calculations of the latest term for endings and beginnings of activity. Calculation of the above parameters is not necessary in terms of a general model of problems. The same is determined with subsequent application of software for PM.

Paragraph 8.2. Unknown for beginnings and endings of activities are not always the earliest times from the usual analysis on the project. Namely:

The linear conditions (5) replace non-linear definitions (15) for earlier beginning of each $A_{i}$ which depend from more $A_{\lambda}$ (the earliest beginning $x_{i}^{E}$ for $A_{i}$ is equal to the earliest ending of $y_{\lambda}^{E}$ for $A_{\lambda}$ which is ending last).

The linear conditions (8) replace non-linear conditions (16) for ending of the project (duration, respectively the earlier and the latest ending of the project $T_{p}$ is equal to the earliest ending $y_{i}^{E}$ for $A_{i}$ from the set of activities without follower which ending tha last).

$$
\begin{gathered}
x_{i}^{E}=\max _{\lambda \in R_{i}^{-}} y_{\lambda}^{E}, i \in I \wedge R_{i}^{-} \neq \varnothing \\
T_{p}=\max _{i} y_{i}^{E}, i \in I \wedge R_{i}^{+}=\varnothing
\end{gathered}
$$

Paragraph 9. The general mathematical model of problem 3.b.1 arises by omitting restrictions (10) that consider available capacities of performers, and conditions (12) for the corresponding binary variables of the second type.

\subsubsection{Resolving of models}

Algorithm 1. Multi-criteria model 3.b.1 is solved with the simpliest combined application method of $\varepsilon$-limitation and lexicographical methods, using software for mixed-integer linear programming. There are determined appropriate Pareto-optimal solutions or Paretosolutions.

Step 1. There are determined minimal project costs for the given duration of the project in accordance with the method of PERT/COST. Permissible duration times are considered starting from the normal duration of the project of $T_{p}=M$ and is ended with the forced duration of $T_{p}=m$. There is applied the metodh of $\varepsilon$-limitation and is determined extreme Pareto-solutions from the standpoint of criteria of the first level significance.

Step 2. With each solution from the step 1 is performed conditional maximization of costs of the favoured performers in accordance with their priorities. There is applied the lexicographical method for costs of the mentioned performers (as a criterion of low level significance), with conditions that do not disrupt the earned values for duration and the project costs (as a criterion of higher level significance).

Step 3. Chosen is the solution for the application, as the most acceptable solution under the given operational conditions. Prepared is an appropriate project plan using a standard software for PM. On the basis of the requested start date of the project and adopted calendar is determined the appropriate elements of the project: beginning and ending dates of activities, dates of completion of the project, the costs for the corresponding periods and the like.

Paragraph 10. Solution of the model 3.b.1 in the mathematical sense makes the set of all Pareto-solutions. However, in practice it is appropriate to specify only the selected Pareto solutions. It can be solutions primarily with the characteristic values for the duration and costs of the project. Then, in the context of these values are found solutions with the most acceptable costs for certain favored performers, who have more priorities over others.

Algorithm 2. Multicriteria model of 3.B.2 is not easily solved by using linear programming. Therefore, it is relatively complicated to use restrictions (10) for the available capacities of performers. Due to this, easier is an interactive application of software for the PM that supports leveling of resources.

Stage 1. Determined is the selected solutions of the model 3.b.1 using the algorithm 1.

Stage2. With every decision from stage 1 is defined the project plan using the software for PM. Then are added data for the required and available capacities of relevant performers in accordance with the relations (10). Followed is the leveling of resources by reducing the required capacity of performers in their available limits. It further observes the resulting minimum duration of the project.

If is not extended duration of the project from stage 1 , is obtained Pareto-solution that stands out in a matching set of $E_{\text {Par }}$.

If the extended duration of the project from stage 1, the obtained solution is not Pareto-optimal.

Stage 3. From set $E_{\text {Par }}$ is selected the most acceptable solution for application.

\section{ILLUSTRATIVE EXAMPLE}

Let be considered the problem of 3.2.1 for the project with $m=9$ activities $A_{i}, \quad i \in I=\{1, \ldots, 9\}$, which have dependencies of the type 'Finish to Start' (Figure 2). There are $n=4$ potential performers of $B_{j}$, $j \in J=\{1,2,3,4\}$. There are determined the required for activities and the performers (Table 2). Duration of activities has been given in weeks and the costs are shown in monetary units (m.u.).

Normal duration activity times $\left(t_{n}\right)_{i}$ determine normal project duration of $T_{p}=M=20$ weeks, when the normal activity costs $\left(c_{n}\right)_{i}$ give forced total project costs $C_{p}(M)=130$ n.j. Forced times of all activities $\left(t_{u}\right)_{i}$ and corresponding forced costs $\left(c_{u}\right)_{i}$ determine forced project duration $T_{p}=m=14$ weeks with the forced total project 
costs $C_{p}(m)=174$ n.j. However, will be proven that the forced project duration can be achieved with the lesser total costs including an amount of $C_{p} *(m)=166$ m.u.

Warning 4.1. Observed are the cases that the potential performers of the same stages have similar variants in time and costs. Also, any performer has a favorable variation in relation to one or more other performers on the same stage. Examples:

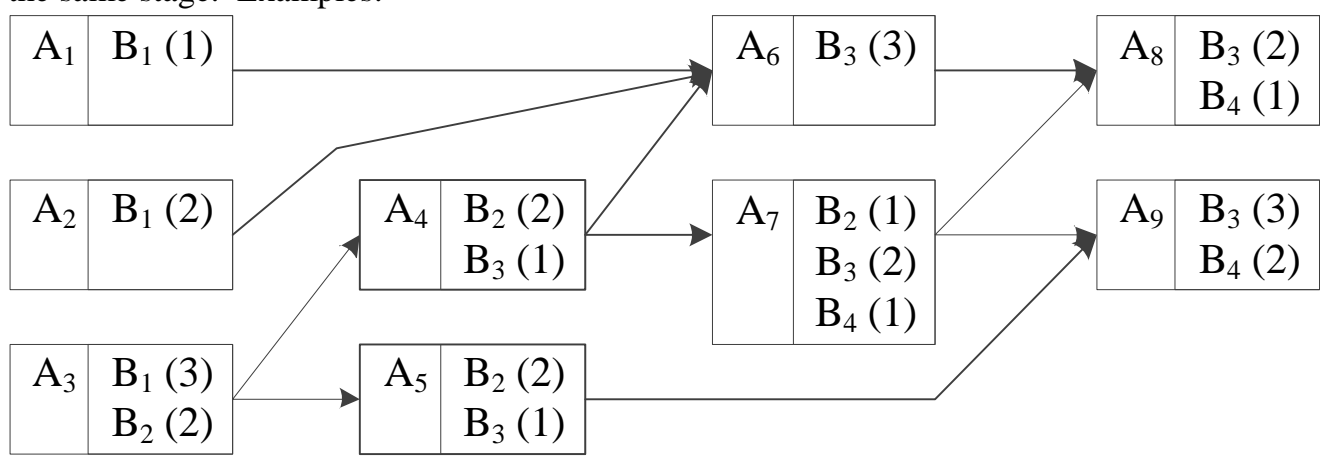

Figure 2. Project network with $A_{i}, B_{j}$ and $d_{i j}, i \in I, j \in J_{i}$
Warning 4.2. Can be omitted the consideration of adverse variations of parameters. This reduces the number of binary variables of the first type, or dimensions of mathematical models. However, this does not affect the resolution of the model and adverse variants will not be selected.
$A_{3}$ has two similar variants for $B_{1}$ i $B_{2}: D_{311}=D_{321}$ i $D_{312}=D_{322}$

$A_{4}$ has better variant $D_{422}$ for $B_{2}$ in relation to $D_{432}$ for $B_{3}$, due to $t_{422}=t_{432}, c_{422}<c_{432}$
By shortening the time of the project for the 1 week (Table 3, Figure 3) is determined the Pareto-solution with the matching minimal project costs $C_{p} *\left(T_{p}\right)$. In accordance witht the adopted lexicographic order of criteria significance arise the following solutions:

Tabela 2. Polazni podaci projekta (različite $D_{i j}$ nekih potencijalnih $B_{j}$ iste faze $A_{i}$ )

\begin{tabular}{|c|c|c|c|c|c|c|c|c|c|c|c|c|c|c|}
\hline \multirow{3}{*}{\begin{tabular}{|c|} 
Phases \\
$A_{i}$ \\
\end{tabular}} & \multirow{3}{*}{\begin{tabular}{|c|} 
Predecessors \\
$K_{i}$
\end{tabular}} & \multirow{3}{*}{\begin{tabular}{|c|} 
Contractors \\
$B_{j}$ \\
\end{tabular}} & \multirow{2}{*}{\multicolumn{2}{|c|}{\begin{tabular}{|c|c|}
\multicolumn{2}{|c|}{ Variants $D_{i j v}$} \\
Number & Indexes \\
\end{tabular}}} & \multirow{2}{*}{\multicolumn{3}{|c|}{ Durations }} & \multirow{2}{*}{\multicolumn{3}{|c|}{ Costs }} & \multicolumn{2}{|c|}{ Normal } & \multicolumn{2}{|c|}{ Crashed } \\
\hline & & & & & & & & & & & \multirow{2}{*}{$\begin{array}{l}\text { Dur. } \\
\left(t_{n}\right)_{i}\end{array}$} & \multirow{2}{*}{$\begin{array}{l}\text { Cost } \\
\left(c_{n}\right)_{i}\end{array}$} & \multirow{2}{*}{$\frac{\text { Dur. }}{\left(t_{u}\right)_{i}}$} & \multirow{2}{*}{$\begin{array}{l}\text { Cost } \\
\left(c_{u}\right)_{i}\end{array}$} \\
\hline & & & $d_{i j}$ & $V_{i j}$ & $t_{i j 1}$ & $t_{i j 2}$ & $t_{i j 3}$ & $c_{i j 1}$ & $c_{i j 2}$ & $c_{i j 3}$ & & & & \\
\hline$A_{1}$ & $\varnothing$ & $B_{1}$ & 1 & $\{1\}$ & 4 & - & - & 14 & - & - & 4 & 14 & 4 & 14 \\
\hline$A_{2}$ & $\varnothing$ & $B_{1}$ & 2 & $\{1,2\}$ & 3 & 2 & - & 13 & 16 & - & 3 & 13 & 2 & 16 \\
\hline \multirow{2}{*}{$A_{3}$} & \multirow{2}{*}{$\varnothing$} & $B_{1}$ & 3 & $\{1,2,3\}$ & 5 & 4 & 3 & 15 & 20 & 25 & \multirow{2}{*}{5} & \multirow{2}{*}{15} & \multirow{2}{*}{3} & \multirow{2}{*}{25} \\
\hline & & $B_{2}$ & 2 & $\{1,2\}$ & 5 & 4 & - & 15 & 20 & - & & & & \\
\hline \multirow{2}{*}{$A_{4}$} & \multirow{2}{*}{3} & $B_{2}$ & 2 & $\{1,2\}$ & 5 & 4 & - & 15 & 17 & - & \multirow{2}{*}{5} & \multirow{2}{*}{15} & \multirow{2}{*}{4} & \multirow{2}{*}{17} \\
\hline & & $B_{3}$ & 1 & $\{2\}$ & - & 4 & - & - & 18 & - & & & & \\
\hline \multirow{2}{*}{$A_{5}$} & \multirow{2}{*}{3} & $B_{2}$ & 2 & $\{1,2\}$ & 4 & 3 & - & 14 & 15 & - & \multirow{2}{*}{4} & \multirow{2}{*}{14} & \multirow{2}{*}{3} & \multirow{2}{*}{15} \\
\hline & & $B_{3}$ & 1 & $\{1\}$ & 5 & - & - & 14 & - & - & & & & \\
\hline$A_{6}$ & $\{1,2,4\}$ & $B_{3}$ & 3 & $\{1,2,3\}$ & 6 & 5 & 4 & 16 & 22 & 30 & 6 & 16 & 4 & 30 \\
\hline \multirow{3}{*}{$A_{7}$} & \multirow{3}{*}{4} & $B_{2}$ & 1 & $\{1\}$ & 4 & - & & 14 & - & & & & & \\
\hline & & $B_{3}$ & 2 & $\{1,2\}$ & 4 & 3 & & 15 & 18 & & 4 & 14 & 3 & 18 \\
\hline & & $B_{4}$ & 1 & $\{2\}$ & - & 3 & & & 20 & & & & & \\
\hline & & $B_{3}$ & 2 & $\{1,2\}$ & 4 & 3 & - & 14 & 16 & - & 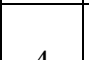 & & 2 & \\
\hline$A_{8}$ & $\{6,7\}$ & $B_{4}$ & 1 & $\{1\}$ & 4 & - & - & 17 & - & - & 4 & 14 & 3 & 16 \\
\hline$\Delta$ & 557 & $B_{3}$ & 2 & $\{1,2,3\}$ & 5 & 4 & 3 & 15 & 19 & 23 & 5 & 15 & 3 & 32 \\
\hline$A_{9}$ & $\{5,7\}$ & $B_{4}$ & 3 & $\{1,2\}$ & 5 & 4 & - & 16 & 18 & - & 5 & 15 & 3 & 23 \\
\hline & & & & & & & & & & & \begin{tabular}{|l|} 
\\
$=20$
\end{tabular} & $\begin{array}{c}C_{p}(M) \\
=130\end{array}$ & $\begin{array}{l}m \\
=14\end{array}$ & $\begin{array}{l}C_{p}(\mathrm{~m}) \\
=174\end{array}$ \\
\hline
\end{tabular}


Table 3. All Pareto-solutions for $T_{p}$ and $C_{p}$ with the best consequences $C_{j}{ }^{*}\left(T_{p}, C_{p}\right), j \in J$

\begin{tabular}{|c|c|c|c|c|c|c|c|c|c|c|c|c|}
\hline \multicolumn{4}{|c|}{ Solutions } & 1 & 2.1 & 2.2 & 3 & 4 & 5 & 6 & 7 & Warnings \\
\hline \multirow{2}{*}{\multicolumn{3}{|c|}{ Optimization }} & $T_{p}$ & 20 & \multicolumn{2}{|c|}{19} & 18 & 17 & 16 & 15 & 14 & $T_{p}^{*}=14$ \\
\hline & & & $C_{p}$ & 130 & \multicolumn{2}{|c|}{132} & 134 & 139 & 144 & 153 & 166 & $C_{p}{ }^{*}=130$ \\
\hline \multirow{4}{*}{\multicolumn{3}{|c|}{$\begin{array}{l}\text { Determination of } \\
\text { the best } \\
\text { consequences }\end{array}$}} & $C_{1}$ & 42 & \multicolumn{2}{|c|}{42} & 42 & 47 & 52 & 52 & 52 & $C_{1} *=52$ \\
\hline & & & $C_{2}$ & 43 & 45 & 43 & 45 & 45 & 45 & 45 & 45 & $C_{2} *=45$ \\
\hline & & & $C_{3}$ & 45 & 45 & 47 & 47 & 47 & 47 & 56 & 69 & $C_{3}^{*}=69$ \\
\hline & & & $C_{4}$ & 0 & \multicolumn{2}{|c|}{0} & 0 & 0 & 0 & 0 & 0 & $C_{4}{ }^{*}=0$ \\
\hline \multirow{5}{*}{ 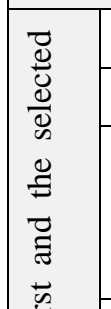 } & $A_{1}$ & $B_{1}$ & $h_{111}$ & 4 & 4 & 4 & 4 & 4 & 4 & 4 & 4 & $t_{u}=t_{n}=4$ \\
\hline & $A_{2}$ & $B_{1}$ & $h_{211}$ & 3 & 3 & 3 & 3 & 3 & 3 & 3 & 3 & NOT $t_{u}=2$ \\
\hline & \multirow{3}{*}{$A_{3}$} & \multirow{3}{*}{$B_{1}$} & $h_{311}$ & 5 & 5 & 5 & $5 \downarrow$ & - & - & - & - & \multirow[b]{3}{*}{ YES $t_{u}=3$} \\
\hline & & & $h_{312}$ & - & - & - & - & $4 \downarrow$ & . & . & . & \\
\hline & & & $h_{313}$ & - & - & - & - & - & 3 & 3 & 3 & \\
\hline 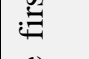 & \multirow{2}{*}{$A_{4}$} & \multirow{2}{*}{$B_{2}$} & $h_{421}$ & $5 \downarrow$ & - & $5 \downarrow$ & - & - & - & - & - & \multirow[b]{2}{*}{ YES $t_{u}=4$} \\
\hline$\cong$ & & & $h_{422}$ & - & $4 \uparrow$ & - & 4 & 4 & 4 & 4 & 4 & \\
\hline $\begin{array}{l}\text { U } \\
\text { n }\end{array}$ & $A_{5}$ & $B_{2}$ & $h_{521}$ & 4 & 4 & 4 & 4 & 4 & 4 & 4 & 4 & NOT $t_{u}=3$ \\
\hline . & \multirow{3}{*}{$A_{6}$} & \multirow{3}{*}{$B_{3}$} & $h_{631}$ & 6 & 6 & 6 & 6 & 6 & $6 \downarrow$ & - & - & \multirow[b]{3}{*}{ YES $t_{u}=4$} \\
\hline$\stackrel{\tilde{D}}{>}$ & & & $h_{632}$ & - & - & - & - & - & - & $5 \downarrow$ & & \\
\hline 気 & & & $h_{633}$ & - & - & - & - & - & - & - & 4 & \\
\hline 0 & $A_{7}$ & $B_{2}$ & $h_{721}$ & 4 & 4 & 4 & 4 & 4 & 4 & 4 & 4 & NOT $t_{u}=3$ \\
\hline 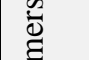 & \multirow{2}{*}{$A_{8}$} & \multirow{2}{*}{$B_{3}$} & $h_{831}$ & 4 & $4 \downarrow$ & - & - & - & - & - & - & \multirow[b]{2}{*}{ YES $t_{u}=3$} \\
\hline E⿱ & & & $h_{832}$ & - & - & 3 & 3 & 3 & 3 & 3 & 3 & \\
\hline \multirow{3}{*}{ 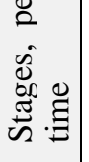 } & \multirow{3}{*}{$A_{9}$} & \multirow{3}{*}{$B_{3}$} & $h_{931}$ & 5 & 5 & 5 & 5 & 5 & $5 \downarrow$ & - & - & \multirow[b]{3}{*}{ YES $t_{u}=3$} \\
\hline & & & $h_{932}$ & - & - & - & - & - & - & $4 \downarrow$ & - & \\
\hline & & & $h_{933}$ & - & - & - & - & - & - & - & 3 & \\
\hline
\end{tabular}

Solutions 1, 2.1, 3 to 7 correspond to the priorities $\left(T_{p}, C_{p}\right) \gg C_{1} \gg C_{2} \gg C_{3} \gg C_{4}$.

All solutions 1 to 7 are determined with priorities $\left(T_{p}, C_{p}\right) \gg C_{1} \gg\left(C_{2}, C_{3}\right)>C_{4}$.

Table shows the values of criteria and the selected performers of $B_{j}$ with the times $t_{i j v}$ for stages $i A_{i}$ in accordance with the selected variants of $D_{i j v}$, that have binary variables $h_{i j v}=1$. Warnings 'YES $t_{u}{ }^{\prime}$ from the last column indicate which stages are shortened at forced times in the last solution 7 or any other previous solution. Solution for the forced project duration of $T_{p}{ }^{*}=m=14$ weeks have the characteristics from continuation, from the standpoint of optimal times and costs, $t_{i}{ }^{*}$ i $c_{i}{ }^{*}$.

$A_{1}$ could not be shortened, it has $t_{1}^{*}=t_{u}=t_{n}=4$ i $c_{1} *=c_{u}=c_{n}=4$

$A_{2}, A_{5}$ i $A_{7}$ are partially shortened, they have $t_{i}{ }^{*}$ $>\left(t_{u}\right)_{i}$ i $c_{i}^{*}=c_{i}\left(t_{i}^{*}\right)<\left(c_{u}\right)_{i}$
Other stages were shortened completely, they have $t_{i}^{*}=\left(t_{u}\right)_{i} \mathrm{i}^{c_{i}}{ }^{*}=\left(c_{u}\right)_{i}$

The mentioned shortening of stages have enabled achievement of lower total project costs $C_{p} *(m)=166$ m.u. compared to the costs $C_{p}(m)=174$ m.u. when all stages have forced times $\left(t_{u}\right)_{i}$ and forced costs $\left(c_{u}\right)_{i}$. There has been achieved saving amounting $C_{p}(m)-C_{p} *(m)=174-166=8$ m.u., respectively $4,60 \%$.

On the basis of the analysis of the the achieved solutions the following conclusions are performed:

It's not necessary to engage the pergormer $B_{4}$, since all solutions have $C_{4}=0$.

When the criteria are equal $C_{2}$ and $C_{3}$, only for $T_{p}=19$ with $C_{p}{ }^{*}=132$ there are two alternatives of Pareto-solution: solution 2.1 with $C_{2}=C_{3}=45$, and solution 2.2 with $C_{2}=43<C_{3}=47$. 
Ideal values of criteria for the project are the minimum duration $T_{p}{ }^{*}=14$ with solution 7 , and minimum costs $C_{p} *=130$ with solutions 1 .

Conditioned ideal values for the costs of the performers $C_{j} *\left(T_{p}, C_{p} *\left(T_{p}\right)\right)$ amounts $C_{1} *=52$ (solutions $5,6,7$ ), $C_{2} *=45$ (solutions 3 to 7 ), and $C_{3} *$ = 59 (solution 7).

The selection of the final solution is carried out on dependency from acceptance of time and project costs. If adopted $T_{p}=19$ sa $C_{p}=132$, is selected solution 4.1 if is favoured the performer $B_{1}$ in relation to $B_{2}$, respectively solution 4.2 if $B_{2}$ has higher significance than $B_{1}$.

\section{CONCLUSION}

This paper shows classification problem of choice of the project performer from the set of potential performers who are qualified for the relevant works. There was carried out the selection of more performers for specific works, according to their specialties, and not the choice of one performer for the project as a whole. The basic requirement is that for any stage selects only one performer. There were formed three groups of problems, each group with two subgroups and each subgroup with two types of data for the working capacity of potential performers.

From the standpoint of the project was carried out minimization of the duration and costs (according to the method of PERT/COST), as a criterion of a higher level of significance. Then was performed conditional maximization of criteria of a lower level of significance the costs of the performers, so as not to worsen the realized values for the criteria of the project (method $\varepsilon$-limitation). Potential performers are defined by the appropriate number of priorities. Thus is determined the set of all or only characteristic of Pareto-optimal solutions among which selects the best solution for the application.

There was defined a general mathematical model for the last problem 3.a.2 which included the problem 3.a.1. There were proposed algorithms for solving both models. There has been displayed resolving 3.a.1 on a hypothetical project with 9 stages and 4 potential performers.

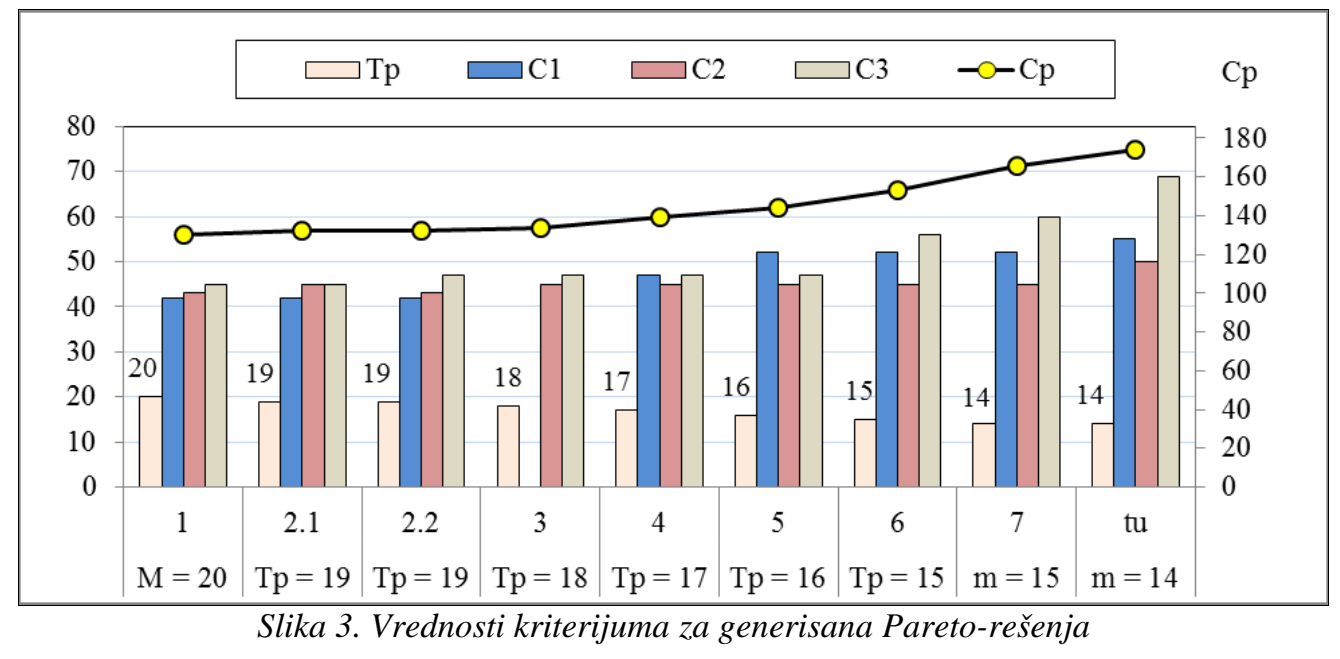

\section{REFERENCES}

[1] J.R. Meredth, et al., "Project Management in Practice," 5th edition, Wiley and Sons, (2013).

[2] C. Hendrickson, "Project Management for Construction, Department of Civil and Environmental Engineering,” Carnegie Mellon University, Pittsburgh, (2008).

[3] I. Nikolić, S. Božilović, "Kvantitativne metode i modeli u menadžmentu - Odabrani problemi u graditeljstvu - Primena softvera WinQSB i Expert Choice," Univerzitet Union, Fakultet za graditeljski menadžment i Fakultet za preduzetnički biznis (sada pripadaju Univerzitetu Union - "Nikola Tesla"), Beograd, (2009).

[4] M. Ehrgott, "Multicriteria optimization - Lecture notes in economics and mathematical systems," SpringerVerlag Berlin, (2000).
[5] I. Nikolić, S. Borović, "Višekriterijumska optimizacija - Metode, primena u logistici i softver," Centar vojnih škola, Beograd, (1996).

[6] Z. Božilović, N. Nikolić, "Dva pristupa izboru učesnika na projektu razmatrajući vremena i troškove," Proceedings of XX International Conference "YuInfo 2014, Kopaonik (Serbia) 09 March-13 March 2014, pp. 200-205, (2014)

[7] Z. Božilović, N. Nikolić, “Some criteria and restrictions on the selection of contractors on a project with options of data to the duration and costs of activities," Proceedings of V International Conference "Life Cycle Engineering and Managemant”, Belgrade (Serbia) 27 June -28 June 2014, pp. 304-309, (2014)

[8] Z. Božilović, N. Nikolić, “Optimalni izbor više izvođača građevinskog projekta razmatranjem prioriteta i kapaciteta potencijalnih izvođača," Proceedings of XLI International Conference "SYM- 
OP-IS 2014", Divčibare (Serbia) 16 September -10 September 2014, pp. 927-932, (2014

[9] Z. Božilović, "Klasifikacija problema izbora izvođača projekta kada neke aktivnosti imaju više potencijalnih izvođača i / ili više varijanti za vreme i troškove“, Proceedings of XVII International Conference “Dependability and Quality Management”, Prijevor (Serbia) (Serbia) 25 Jun - 26 Jun 2015, pp. 491-494, (2015).

[10] J. J. Ahonen, P. Savolainen, H. Merikoski, and J. Nevalainen, "Reported project management effort, project size, and contract type,” J. Syst. Softw., vol. 109, pp. 205-213, Aug. 2015.
[11] G. Ellis, Project Management in Product Development. Elsevier, 2016.

[12] B. Ekrot, A. Kock, and H. G. Gemünden, "Retaining project management competence - Antecedents and consequences,” Int. J. Proj. Manag., vol. 34, no. 2, pp. 145-157, Feb. 2016.

[13] Bogićević, Z., Pejčev, A., Marković. G: materials handling equipment selection using integrated fuzzy AHP and Vikor methods', IMK -14- Research \& Development in heavy machinery, vol 21,(2015) 3, p.p. EN87-93, 2015.

[14] M. Note, Project Management for Information Professionals. Elsevier, 2016 